\title{
Trisection Open-Loop Varacter-Based Tunable Filter for 5G Wireless Communications
}

\author{
Yasir I. A. Al-Yasir ${ }^{1}$, Y. Tu ${ }^{1}$, Abdolrauf Alhaddad ${ }^{1,2}$, Raed Abd-Alhameed ${ }^{1}$ \\ ${ }^{1}$ Faculty of Engineering and Informatics, University of Bradford, Bradford, UK, \\ ${ }^{2}$ Converting Industries Company, Light industrial Area, Royal commission, Yanbu, Yanbu \\ Alsinaya 41912, P.O. Box 32171, Saudi Arabia \\ Y.I.A.Al-Yasir@bradford.ac.uk
}

\begin{abstract}
In this manuscript, a very compact planar reconfigurable bandpass filter (BPF) operating from 3.4 to $3.8 \mathrm{GHz}$ spectrum bandwidth for fifth-generation $5 \mathrm{G}$ wireless communications is proposed. The microstrip band-pass filter (BPF) employes three-ring resonators with $50 \Omega$ transmission line impedances for input and output ports. The mutual coupling coefficients are controlled to achieve the required frequency response with three poles bandpass Butterworth properties. Varactor switch and biasing circuits are modeled to control the centre frequency in the required bands. The presented tunable filter is designed on Rogers RO3010 dielectric material with a relative permittivity of 10.2 and a very small size of $17 \times 5 \times 1.27 \mathrm{~mm}^{3}$. The introduced reconfigurable BPF is designed and optimized using CST tool.
\end{abstract}

Keywords: planar, band-pass, reconfigurable, frequency, Rogers.

\section{Introduction}

Radio frequency noise is an increasingly serious issue in modern wireless communication applications such as 5G and wide-band radar systems [1-18]. Microstrip band-pass filters are generally used to filter noise signals and unwanted frequencies in wireless communication applications [19], particularly in radio frequencies and microwave communications due to their effective rejection of spurious frequencies. Nowadays, $5 \mathrm{G}$ wireless communication technology is being considered for use in $700 \mathrm{MHz}, 3.6 \mathrm{GHz}$ and $26 \mathrm{GHz}$ bands [20]. Band-pass filters are useful units in many $5 \mathrm{G}$ systems for rejecting unwanted signals. In addition, there are particular requirements for band-pass filters in such systems [21,22]. A band-pass filter contains a number of coupled resonators, and the dimensions of the distributed elements and the number of resonators proposed defines the filter characteristics. Consequently, most microstrip filter miniaturization techniques seek to minimize one or other of these quantities [23-31]. A variety of structures and methods have been proposed for microstrip tunable filters such as combline, hairpin, parallel-coupled line, step impedance, and stub impedance [21-39].

A planar microwave tunable bandpass filter using a varactor diode is investigated for controlling a constant bandwidth [32]. Tuning the resonant frequency can be achieved simply by controlling the resonant frequencies for both the odd and even modes as there is not any coupling between these modes. In [33], a planar tunable filter is designed by using two varactor diodes to adjust two transmission zeros (TZs). The resonant frequency and the bandwidth of this filter are adjusted with a wide tuning range of about $590 \mathrm{MHz}(1.5-2.1 \mathrm{GHz})$ by controlling the 
DC biasing voltage across to the varactor diodes. In [37], a compact reconfigurable microstrip filter with constant characteristics is presented. By controlling the DC biasing voltage of four varactor diodes, the designed filter is reconfigurable from 1.8 to $1.9 \mathrm{GHz}$ with a $5 \%$ fractional bandwidth.

In recent years, many designs of reconfigurable microstrip filters have been proposed and investigated. Chen et al. [38] designed a second-order microwave reconfigurable filter with a compact size and constant bandwidth. Two varactor diodes are used to tune the resonant frequency between the higher and lower modes of operation with a range of 1.2 to $1.9 \mathrm{GHz}$ and constant fractional bandwidth of $39 \mathrm{MHz}$. The properties of small size $(0.06 \lambda \mathrm{g} \times 0.27 \lambda \mathrm{g})$, continuous reconfigurable capacity, simple design, and wide-ranging frequency made the designed filter suitable for the recent wireless communications. Ebrahimi et al. [39] proposed a notch tunable bandstop filter by using two varactor diodes. The designed second-order filter illustrates a continuous tuning range of the resonant frequency of $0.7-1 \mathrm{GHz}$ with a compact structure of $0.15 \lambda \mathrm{g} \times 0.17 \lambda \mathrm{g}$ size. Unlike the previous structures, the inductive coupling is obtained by another inductor created in the ground layer of the microstrip.

In this paper, a compact three-poles planar reconfigurable filter is designed using the CST tool to cover the frequency band of 3.4 to $3.8 \mathrm{GHz}$, suitable for $5 \mathrm{G}$ wireless communication applications. By adjusting the DC biasing voltage across to the varactor diodes, both the resonant frequency and the bandwidth of this filter are adjusted with a wide tuning range of about $400 \mathrm{MHz}(3.4-3.8 \mathrm{GHz})$. Very good insertion loss of $1 \mathrm{~dB}$ has been achieved. Also, it is significant that this design can be easily developed and integrated with antenna design [40], to create the so-called "filtenna" [41-46]. The filter design and its performance are presented and discussed in the next coming sections."

\section{Reconfigurable planar BPF design}

The geometry of the proposed design is shown in Fig. 1. Three-ring resonators fed by two ports $50 \Omega$ input impedance are used for reducing the physical size without the need for vias. The filter is designed with a transmission line feed and Rogers RO3010 substrate is used, with $\mathrm{h}=$ $1.27 \mathrm{~mm}, \varepsilon r=10.2$ and loss tangent $=0.0022$. The frequency $3.6 \mathrm{GHz}$ is chosen as the resonance frequency because this frequency is suitable for $5 \mathrm{G}$. Frequency reconfigurability is important for these designs to get tunability for multi-band systems and to cover the required variations. Using varactors is a famous technique for reconfigurable filters. Nevertheless, the position of the varactor effects the performance of the filter. The filter in this paper is designed with varactor diode and the biasing circuit necessary to tune both the resonant frequency and bandwidth characteristics. Two Inductors $(\mathrm{L} 1=\mathrm{L} 2=10 \mathrm{nH})$ are used as radio frequency (RF) chokes to limit and reduce the leakage of the RF signal into the biasing circuit and powering wires by acting as an open circuit to the RF signal at the two ends of the switches. The optimized dimensions are achieved by using the built-in optimizer embedded with the CST software. The CST time domain solver has been used with 10 lines per wavelength as mesh density control properties. The dimensions of this filter are optimized to ensure good matching at the tuning range. The configuration of this filter and its optimized dimensions are shown in Fig. 1 and Table I, respectively. 
The biasing circuit of the proposed tunable filter with the SPICE representation for the varactor is modeled as illustrated in Fig. 2. Practical switches (SMV1234) manufactured by incorporation of Skyworks Solutions with a size $1.5 \times 0.7 \mathrm{~mm} 2$ can be used as a varactor switch.

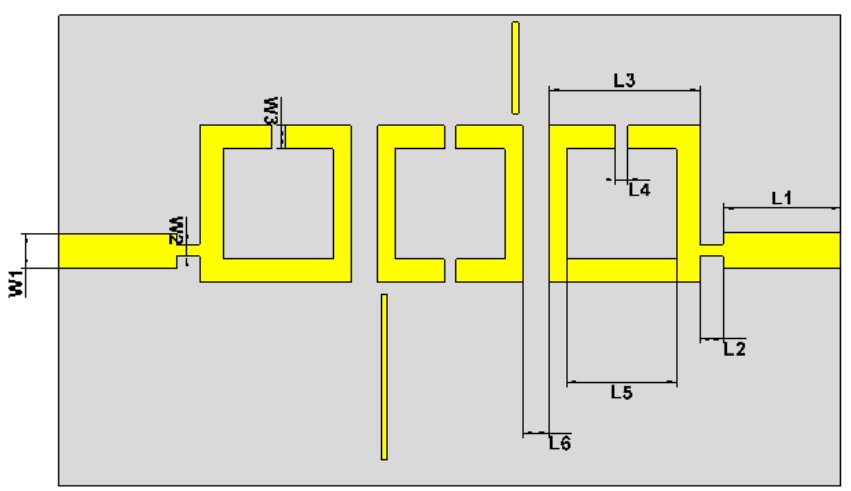

(a)

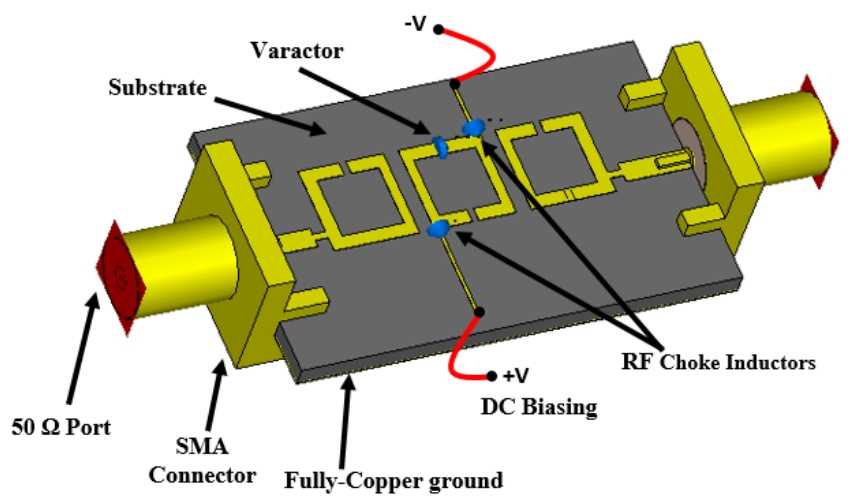

(b)

Fig. 1. The geometry of the designed tunable BPF: (a) 2D geometry $\quad$ (b) 3D structure.

TABLE I. THE OPTIMIZED DIMENSIONS OF THE ANTENNA (UNITS IN MM)

\begin{tabular}{|c|c|c|c|c|c|c|c|c|}
\hline L1 & L2 & L3 & L4 & L5 & L6 & W1 & W2 & W3 \\
\hline 3.9 & 0.9 & 4.8 & 0.5 & 3.8 & 0.9 & 1.2 & 0.43 & 0.9 \\
\hline
\end{tabular}




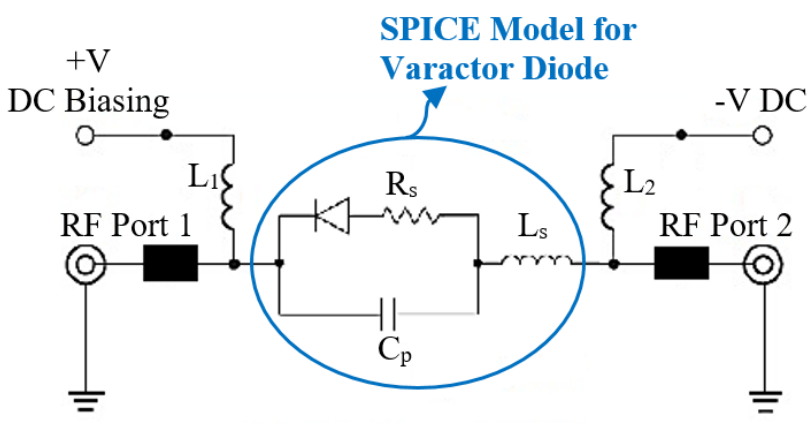

Fig. 2. Biasing circuit used for the proposed tunable filter.

\section{Three-pole tunable filter performance}

In this section, the performance of the tunable filter is studied in terms of return loss and insertion loss. The simulation results are generated using CST studio software. The simulation results for the return loss of proposed three-pole microstrip filter in Fig. 3 shows that by altering the biasing voltages of the varactor, the capacitance values (CT) will be changed accordingly with different values $(2.6,3.3,4.8,6$ and $8.1 \mathrm{pF})$. It is shown that by increasing the capacitance of the varactor, the return loss will be reduced in tuned in the desired band necessary by the $5 \mathrm{G}$ application that is 3.4- 3.8 GHz. Good return loss is achieved during the overall band to be between $-20 \mathrm{~dB}$ to $-37 \mathrm{~dB}$. In Fig. 4, the simulated values for the insertion loss have been achieved with different values corresponded to the values obtained in Fig. 3. Good insertion loss resulted during the tuning range of the resonant frequency with values around the $-1 \mathrm{~dB}$.

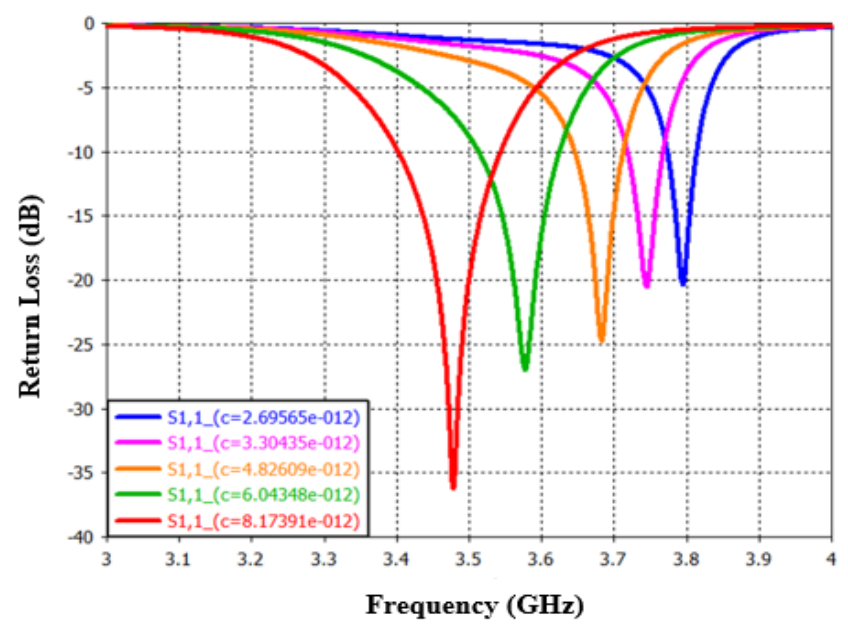

Fig. 3. Simulated results for S11 with different biasing voltages. 


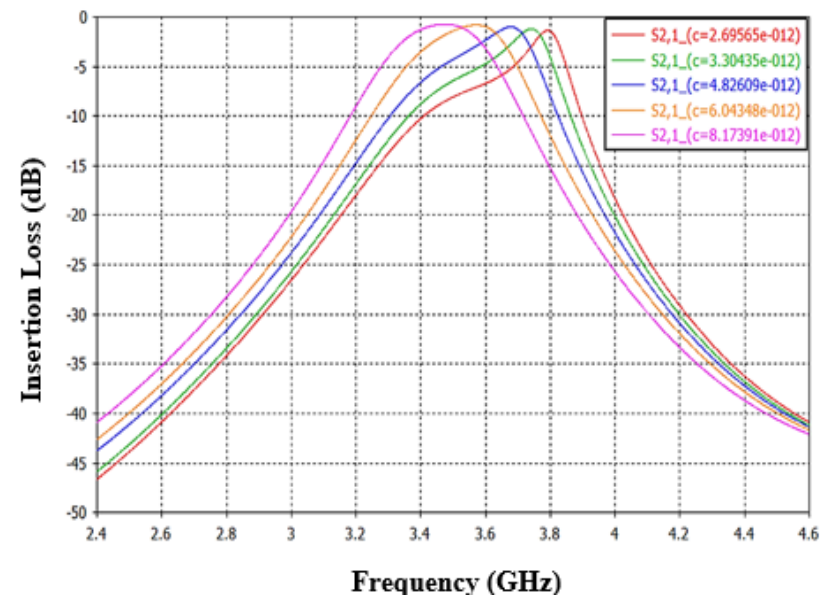

Fig. 4. Simulated results for S21 with different biasing voltages.

In addition to the tunability of the resonant frequency, the bandwidth is tuned with different appropriate values. It is clear from Fig. 3 and Fig. 4 that the bandwidth of $10 \mathrm{~dB}$ passband for the designed filter has been tuned in the range (50-130 MHz) according to the biasing of the varactor diode. The characteristics are obtained by using the CST tool, and the results of the parameters are been shown. Table II summaries the biasing circuit parameters achieved by the datasheet and the obtained performance for the reported microstrip filter.

TABLE II. SUMMARY OF THE ACHIEVED PERFORMANCE
\begin{tabular}{|c|c|c|c|c|}
\hline $\begin{array}{c}\text { Voltage } \\
(\mathbf{V})\end{array}$ & $\begin{array}{c}\text { Varactor } \\
\text { Capacitance } \\
(\mathbf{p F})\end{array}$ & $\mathbf{F}_{\mathbf{0}}(\mathbf{G H z})$ & $\begin{array}{c}\mathbf{B W} \\
(\mathbf{M H z})\end{array}$ & $\begin{array}{c}\text { S11 } \\
\mathbf{( d B})\end{array}$ \\
\hline-3.8 & 3.4 & 3.9 & 50 & -22 \\
\hline-32.8 & 3 & 3.8 & 70 & -24 \\
\hline-1.9 & 4 & 3.7 & 80 & -27 \\
\hline-0.89 & 5 & 3.58 & 105 & -29 \\
\hline-0.5 & 7 & 3.48 & 130 & -37 \\
\hline
\end{tabular}

\section{Conclusion}

A proposed compact design for a $5 \mathrm{G}$ reconfigurable-microstrip bandpass filter is presented in this paper with third-order and Butterworth filter properties. The filter is reconfigurable for both the resonant frequency and bandwidth to cover 3.4-3.8 GHz under the control of varactor diode switch. The proposed design exhibits 50-130 MHz bandwidth with return loss between $20 \mathrm{~dB}$ to $-37 \mathrm{~dB}$ and insertion loss around the $-1 \mathrm{~dB}$. Only one varactor diode is used for tuning the filter. The bandpass tunable filter covers the $5 \mathrm{G}$ frequency spectrum for possible use in stationary terminals of different wireless communications and it is suitable for cognitive radio systems as well. 
Acknowledgments. This project has received funding from the European Union's Horizon 2020 research and innovation programme under grant agreement H2020-MSCA-ITN-2016 SECRET-722424.

\section{References}

[1] A. Hussaini, Y. Al-Yasir, k. Voudouris, B. Mohammed, R. Abd-Alhameed, H. Mohammed, I. Elfergani, A. Abdullah, D. Makris, J. Rodriguez, J. Noras, C. Nche, and M. Fonkam, Green Flexible RF for 5G. Fundamentals of 5G Mobile Networks, John Wiley and Sons, pp. 241-272, 2015.

[2] Yasir I.A. Al-Yasir, Hasanain A.H. Al-Behadili, Baha A. Sawadi, Naser Ojaroudi Parchin, Ahmed M. Abdulkhaleq, Abdulkareem S. Abdullah and Raed A. Abd-Alhameed (September 26th 2019). New Radiation Pattern-Reconfigurable 60-GHz Antenna for 5G Communications, IntechOpen, Available from: https://www.intechopen.com/online-first/new-radiation-pattern-reconfigurable-60-ghz-antenna-for5g-communications.

[3] Y. Al-Yasir et al., "Compact tunable microstrip filter with wide-stopband restriction and wide tuning range for 4G and 5g applications," The IET's Antennas and Propagation Conference, 2019, pp. 1-6.

[4] Y. I. Abdulraheem, A. S. Abdullah, H. J. Mohammed, B. A. Mohammed, and R. A. Abd-Alhameed, "Design of Radiation PatternReconfigurable 60-GHz Antenna for 5G Applications," Journal of Telecommunications, vol. 52, no. 4, pp. 1-5, 2014

[5] H. J. Mohammed et al., "Evaluation of genetic algorithms, particle swarm optimisation, and firefly algorithms in antenna design," 2016 13th International Conference on Synthesis, Modeling, Analysis and Simulation Methods and Applications to Circuit Design (SMACD), Lisbon, 2016, pp. 1-4.

[6] Y. I. A. Al-Yasir and R. Abd-Alhameed, "New multi-standard dualwideband and quad-wideband asymmetric step impedance resonator filters with wide stop band restriction," International Journal of RF and Microwave Computer-Aided Engineering, vol. 29, no. 8, p. 1-17, 2019.

[7] Y. I. A. AI-Yasir, N. Ojaroudi Parchin, A. Alabdullah, W. Mshwat, A. Ullah and R. Abd-Alhameed, "New pattern reconfigurable circular disk antenna using two PIN diodes for WiMax/WiFi (IEEE 802. 11 a) applications," 2019 16th International Conference on Synthesis, Modeling, Analysis and Simulation Methods and Applications to Circuit Design (SMACD), Lausanne, Switzerland, 2019, pp. 53-56.

[8] Y. I. A. Al-Yasir et al, "Design, simulation and implementation of very compact dual-band microstrip bandpass filter for 4G and 5G applications," 2019 16th International Conference on Synthesis, Modeling, Analysis and Simulation Methods and Applications to Circuit Design (SMACD), Lausanne, Switzerland, 2019, pp. 41-44.

[9] Y. I. A. Al-Yasir, N. O. Parchin, A. Alabdallah, A. M. Abdulkhaleq, R. A. Abd-Alhameed and J. M. Noras, "Design of Bandpass Tunable Filter for Green Flexible RF for 5G," 2019 IEEE 2nd 5G World Forum (5GWF), Dresden, Germany, 2019, pp. 194-198.

[10] Y. I. A. Al-Yasir et al., "Design, Simulation and Implementation of Very Compact Open-loop Trisection BPF for 5G Communications," 2019 IEEE 2nd 5G World Forum (5GWF), Dresden, Germany, 2019, pp. 189-193.

[11] Y. Al-Yasir, A. S. Abdullah, N. Ojaroudi Parchin, R. A. Abd-Alhameed, and J. M. Noras, "A New PolarizationReconfigurable Antenna for 5G Applications," Electronics, vol. 7, no. 11, p. 293, 2018.

[12] Al-Yasir Y.I.A. et al. (2019) A New Polarization-Reconfigurable Antenna for 5G Wireless Communications. In: Sucasas V., Mantas G., Althunibat S. (eds) Broadband Communications, Networks, and Systems. BROADNETS 2018. Lecture Notes of the Institute for Computer Sciences, Social Informatics and Telecommunications Engineering, vol 263. Springer, Cham.

[13] Y. I. A. Al-Yasir et al., "A Differential-Fed Dual-Polarized High-Gain Filtering Antenna Based on SIW Technology for 5G Applications," 2020 14th European Conference on Antennas and Propagation (EuCAP), Copenhagen, Denmark, 2020, pp. 1-5.

[14] Y. I. A. Al-Yasir et al., "Design of multi-standard single/tri/quint-wideband asymmetric stepped-impedance resonator filters with adjustable TZs," IET Microwaves, Antennas \& Propagation, vol. 13, no. 10, pp. 1637-1645, 14 Aug. 2019.

[15] Y. I. A. Al-Yasir et al., " New High-Gain Differential-Fed Dual-Polarized Filtering Microstrip Antenna for 5G Applications," 2020 14th European Conference on Antennas and Propagation (EuCAP), Copenhagen, Denmark, 2020, pp. $1-5$ 
[16] Y. Al-Yasir, N. Ojaroudi Parchin, R. Abd-Alhameed, A. Abdulkhaleq and J. Noras, "Recent Progress in the Design of 4G/5G Reconfigurable Filters” Electronics”, vol. 8, no. 1, Jan. 2019.

[17] Y. Al-Yasir, Y. Tu, N. Ojaroudi Parchin, I. Elfergani, R. Abd-Alhameed, J. Rodriguez, J. Noras, "Mixed-coupling multi-function quint-wideband asymmetric stepped impedance resonator filter" Microw. and Opt. Tech. Lett. Vol. 61, no. 5, pp1181-1148, Jan. 2019.

[18] Al-Yasir, Y.I.A.; Ojaroudi Parchin, N.; Abdulkhaleq, A.M.; Bakr, M.S.; Abd-Alhameed, R.A. A Survey of Differential-Fed Microstrip Bandpass Filters: Recent Techniques and Challenges. Sensors 2020, 20, 2356.

[19] J.-S. G. Hong and M. J. Lancaster, Microstrip Filters for RF/Microwave, vol. 167, John Wiley and Sons, 2004.

[20] "Ofcom," 8 February 2017. [Online]. Available: https://www.ofcom.org.uk/.

[21] J. S. Jeon, S. T. Kang and H. S. Kim, "GA-optimized compact broadband CRLH band-pass filter using stubinserted interdigital coupled lines," Journal of Electromagnetic Engineering and Science, vol. 15, no. 1, pp. 31 36, 2015.

[22] C. X. Wang, F. Haider, X. Gao, X. H. You, Y. Yang, D. Yuan, H. Aggoune, H. Haas, S. Fletcher and E. Hepsaydir, "Cellular architecture and key technologies for $5 \mathrm{G}$ wireless communication networks," IEEE Commun. Mag., vol. 52, no. 2, pp. 122-130, 2014.

[23] J. Nieto and R. Savleav, "Miniature Coplanar Waveguide and Microstrip Stop-band Filters Using Spiral Resonators," First European Conference on Antennas and Propagation (EuCap), Nice, France, pp. 6 - 10, Nov. 2006.

[24] M. K. T. Al-Nuaimi and W. G. Whittow, "Compact microstrip band stop filter using SRR and CSSR: Design, simulation and results," Fourth European Conference on Antennas and Propagation (EuCAP), Barcelona, Spain, pp. 1-5, April 2010.

[25] A. Mallahzadeh, B. Rahmati, M. Alamolhoda, R. Sharifzadeh, and A. Ghasemi, "Ultra wide stop band LPF with using defected microstrip structures," Sixth European Conference on Antennas and Propagation (EUCAP), Prague, Czech Republic, pp 1-3, March 2012.

[26] R. Hotopan, M. Elena and F. Las-Heras, "Reduced Size C-Band Band-pass Filterwith 2nd Harmonic Suppression," 8th European Conference on Antennas and Propagation (EuCAP), The Hague, Netherlands, April 2014.

[27] Z. Zakaria, M. A. Mutalib, A. Ismail, M. S. M. Isa, M. M. Ismail, A. A. Latiff, N. A. Zainuddin, and W. Y. Sam, "Compact structure of band-pass filter integrated with Defected Microstrip Structure (DMS) for wideband applications," 8th European Conference on Antennas and Propagation (EuCAP), The Hague, Netherlands, pp. 2158-2162, April 2014.

[28] A. Naghar, A. Alejos, O. Aghzout, F. Falcone and M. Sanchez, "C-band parallel coupled bandpass filter with harmonic suppression using open stub and CSRRs," 9th European Conference on Antennas and Propagation (EuCAP), Lisbon, Portugal, 2015.

[29] S. Hao and Q. J. Gu, "A fourth order tunable capacitor coupled microstrip resonator band pass filter," in Proc. IEEE Radio Wireless Symp., , pp. 150-152, Jan. 2015.

[30]E. Pruksawan and A. Lang, "Microstrip tunable bandpass filter with dielectric superstrate for UHF-RFID application," 13th International Conference on Electrical Engineering/Electronics, Computer, Telecommunications and Information Technology (ECTI-CON), Chiang Mai, Thailand, July. 2016.

[31] Y. Al-Yasir, R. Abd-Alhameed, J. Noras, A. Abdulkhaleq and N. Ojaroudi Parchin, "Design of Very Compact Combline Band-Pass Filter for 5G Applications," Loughborough Antennas \& Propagation Conference, Loughborough, UK, 2018.

[32] W. Tang and J.-S. Hong, "Varactor-tuned dual-mode bandpass filters," IEEE Trans. Microw. Theory Techn., vol. 58, no. 8, pp. 2213-2219, Aug. 2010.

[33] J. Long, C. Li, W. Cui, J. Huangfu, and L. Ran, "A tunable microstrip bandpass filter with two independently adjustable transmission zeros,” IEEE Microw. Wireless Compon. Lett., vol. 21, no. 2, pp. 74-76, Feb. 2011.

[34] X.-G. Wang, Y.-H. Cho, and S.-W. Yun, “A tunable combline bandpass filter loaded with series resonator,” IEEE Trans. Microw. Theory Techn., vol. 60, no. 6, pp. 1569-1576, Jun. 2012.

[35] Y.-C. Chiou and G. M. Rebeiz, "Tunable 1.55-2.1 GHz 4-pole elliptic bandpass filter with bandwidth control and $>50 \mathrm{~dB}$ rejection for wireless systems," IEEE Trans. Microw. Theory Techn., vol. 61, no. 1, pp. 117-124, Jan. 2013.

[36] P.-L. Chi, T. Yang, and T.-Y. Tsai, “A fully tunable two-pole bandpass filter,” IEEE Microw. Wireless Compon. Lett., vol. 25, no. 5, pp. 292-294, May 2015.

[37] H.-Y. Tsai, T.-Y. Huang, and R.-B. Wu, "Varactor-tuned compact dualmode tunable filter with constant passband characteristics," IEEE Trans. Compon., Packag., Manuf. Technol., vol. 6, no. 9, pp. 1399-1407, Sep. 2016. 
[38] C.-F. Chen, G.-Y. Wang, and J.-J. Li, "Microstrip Switchable and Fully Tunable Bandpass Filter With Continuous Frequency Tuning Range," IEEE Microw. Wireless Compon. Lett., vol. 28, no. 6, pp. 500-502, June 2018.

[39] A. Ebrahimi, T. Baum, and J. Scott, "Continuously Tunable Dual-Mode Bandstop Filter," IEEE Microw. Wireless Compon. Lett., vol. 28, no. 5, pp. 419-421, May 2018.

[40] Y. Al-Yasir, A. Abdullah, H. Mohammed, R. Abd-Alhameed and J. Noras. "Design of frequency reconfigurable multiband compact antenna using two PIN diodes for WLAN/WiMAX applications," IET Microwaves, Antennas and Propagation, vol. 11, no. 8, pp. 1098-1105, 2017.

[41] H. A. Atallah, A.-R. Abdul Rahman, K. Yoshitomi and P. Pokharel. "Compact frequency reconfigurable filtennas using varactor loaded $\mathrm{t}$-shaped and $\mathrm{h}$-shaped resonators for cognitive radio applications," IET Microwaves, Antennas and Propagation, vol. 10, no. 9, pp. 991-1001, 2016.

[42] Al-Yasir, Y.I.A.; Alkhafaji, M.K.; A. Alhamadani, H.; Ojaroudi Parchin, N.; Elfergani, I.; Saleh, A.L.; Rodriguez, J.; Abd-Alhameed, R.A. A New and Compact Wide-Band Microstrip Filter-Antenna Design for $2.4 \mathrm{GHz}$ ISM Band and 4G Applications. Electronics 2020, 9, 1084.

[43] Al-Yasir, Y.I.A.; A. Alhamadani, H.; Kadhim, A.S.; Ojaroudi Parchin, N.; Saleh, A.L.; Elfergani, I.T.E.; Rodriguez, J.; Abd-Alhameed, R.A. Design of a Wide-Band Microstrip Filtering Antenna with Modified Shaped Slots and SIR Structure. Inventions 2020, 5, 11 .

[44] Mohammed, K.A.; Alhamadani, A.; Al-Yasir, Y.I.A.; Saleh, A.L.; Parchin, N.O.; Abd-Alhameed, R. Study on the effect of the substrate material type and thickness on the performance of the filtering antenna design. TELKOMNIKA Telecommun. Comput. Electron. Control 2020, 18, 72-79.

[45] Abdel-Jabbar, H.; Kadhim, A.S.; Saleh, A.L.; Al-Yasir, Y.I.A.; Parchin, N.O.; Abd-Alhameed, R.A. Design and optimization of microstrip filtering antenna with modified shaped slots and SIR filter to improve the impedance bandwidth. TELKOMNIKA Telecommun. Comput. Electron. Contro 2020, 18, 515-545.

[46] Parchin, N.O.; Al-Yasir, Y.I.A.; Abd-Alhameed, R.A. Microwave/RF Components for $5 G$ Front-End Systems; Avid Science: Telangana, India, 2019; pp. 1-200. 